УДК $339.97+339.92$

\title{
THE ECONOMICS OF INTERNATIONAL STRATEGIC ALLIANCE (ISA): AN ASSESSMENT OF TRANSACTION COST ECONOMICS AND ALLIANCE OUTCOMES
}

\author{
V.A. VASICHEVA \\ postgraduate student of Belarus National Technical University, \\ lecturer of Linnaeus University, Vaxjo, Sweden \\ ЭКОНОМИКА МЕЖДУНАРОДНЫХ СТРАТЕГИЧЕСКИХ АЛЬЯНСОВ: \\ ОЦЕНКА ТЕОРИИ ТРАНСАКЦИОННЫХ ИЗДЕРЖЕК \\ И РЕЗУЛЬТАТОВ ФУНКЦИОНИРОВАНИЯ АЛЬЯНСОВ \\ В.А. ВАСИЧЕВА \\ аспирант Белорусского национального технического университета, \\ преподаватель университета Линнеус, г. Векше, Швеция
}

\begin{abstract}
Аннотация
Одним из способов достижения успешного функиионирования стратегического альянса является обеспечение удовлетворенности фирм-партнеров в сотрудничестве. Основная задача данного исследования заключается в измерении взаимосвязи и корреляции между мотивацией стратегического альянса, стоимостью трансакииионыьх издержек и результатами стратегического альянса. Основная иеель заключается в выявлении ключевых факторов, влияющих на экономику стратегического альянса. В данной статье рассмотрены четыре гипотезы. Данные оценивались с использованием различных статистических методов. Положительные результаты значительно перевешивают отрицательные.

Ключевые слова: стратегический альянс, экономика, мотиваџия, трансакциионные издержки, доверие.
\end{abstract}

\section{Abstract}

One way to achieve successful functioning of strategic alliance is to ensure that partner firms are satisfied. The main task of this research is to measure the interrelationship and correlations between strategic alliance motivations, transaction cost economics, and its strategic alliance outcomes. The main goal is to identify the key factors that influence the economics of strategic alliance. Four hypotheses were tested. The data was assessed using different statistical methods. The positive outcomes significantly outweigh the negative ones.

Key words: strategic alliances, economics, motivation, transaction costs, trust.

\section{INTRODUCTION}

A relationship between organizations contains not only utilitarian economic factors but also psychological behavioral factors such as trust, commitment and satisfaction (Zafirovski, 2005; Zineldin et al. 2014). Even, social exchange theory (SET) is based on economical and psychological behaviorism because the establishing, developing and sustaining human or inter organizational relationships goes beyond the utilitarian economics (Zineldin et al., 2014).

Strategic alliance and inter-organizational relations can be examined from a wide range of theoretical starting points. They include strategic management, organization theory, economic and industrial analysis, network theory, game theory, the sociology and psychology 
theories, to name only the most obvious. Models of bilateral and multilateral (e.g. multi-state coalitions) relationships can also be applied to the study of strategic alliances. May and Tate (2011) found evidences that strategic alliance is determined by economic and socialpsychological variables. More interestingly, the collaboration phenomenon challenges researchers to extend these theories by highlighting the complexity of the inter-organizational relationships. This makes strategic alliance research intellectually challenging. Paavo and Hallikas, 2011).

Despite the increased interests of entering and managing strategic alliances, the field still theoretically and empirically lacks a framework to describe the conditions and dynamics leading to the understand the economics of strategic alliances (Park and Ungson, 2001; Zineldin and Dodourova, 2005; Valent, 2008).In economics and related disciplines, the concept transaction cost can be defined as a cost incurred to make an economic exchange.This study focuses on transaction cost economics and the outcomes of strategic alliances.

According to our knowledge there is no research on the interrelationship between strategic alliance motivations (SAM), transaction cost economics (TCE) and its strategic alliance outcomes (SAO). Thus, the main task of this research is to measure the interrelationship and correlations between SAM, TCE and SAO. The main goal is to identify the key factors that influence the economics of strategic alliance.

\section{RESULTS AND ITS DISCUSSION}

\section{Strategic Alliance (SA)}

According to Chandler's definition (1982), strategy is «the determination of the basic long-term goals and objectives of an enterprise and the adoption of courses of action and the allocation of resources necessary for carrying out those goals»».

«SA is a formal agreement between two or more business organizations to pursue a set of private and common interests through the sharing of resources in contexts involving uncertainty over outcomes. Depending on its purpose, an SA may temporary or enduring». (Ariño, 2003)

So strategic alliances are entered into by two or more partners to pursue long-term goals beneficial for all the partners, and this characteristic differentiates strategic alliances from other forms of partnerships. The prior strategic alliance research have added to our knowledge the main reasons of why strategic alliances forms and the enablers for initiation success and the achieved benefits (e.g. Zineldin, 2002; Zineldin and Jonsson, 2000; Lemoine and Dagnæs, 2003). Most of previous strategic alliance studies suffer from some weaknesses (Dyer and Ouchi, 1993; Geringer and Louis, 1991; Niern, et al., 1995; Brucellaria, 2000; Zineldin and Jonsson, 2000; Wheelen and Hungar, 2000. Zineoldin\&Dodourova, 2005) Some have failed to use formative indicators to differentiate between failed and successful alliances, instead opting for either a descriptive case approach or respondent based reports of alliance existence (Zineldin, et al 2015).

The main result of previous studies on strategic alliances showed that there are noticeable differences in the motives for entering into an alliance (Zineldin, 2005). The culture is also influencing the complexity of strategic alliance relational constructs such as trust, commitment, co-operation, dependence, communication, adaptations and the economics of the alliance in form of costs and financial exchanges and outcomes. SA is also influenced by the experience, previous termination, alliance types, organization size and age. Larger companies tend to gain greater benefits from the SA than smaller firms (Terzivski, 2000; Heimeriks and Duysters, 2007). Rothaemel et al. (2006) found that alliance type and alliance experience moderate the alliance relationships and product development. According to Zineldin et al (2014), the termination of the previous alliance relationships refers to the capability and unique knowledge that firms deploy for the formation, management, and termination of alliances (Lambe et al., 2002; Ziggers et al., 2010). 
The concept value creation (VC) is also a critical motivation for the existence of SA. VC defined by Rai (2013) as the total sum of value that is created during alliance activities. The following approaches have been adopted by rai (2013)to measure the value creation of SA:

(a) financial measures such as firms' profitability, net income, return on investment and market gains and shares;

(b) measures of alliance performance and success in terms of alliance duration, stability, termination, andassessment of partners' ongoing relationship and fit;

(c) subjective measures such as managers' satisfaction with alliance performance and the fulfillment ofstrategic goals;

Understanding the perceived quality of the SA is critical to predict the firm's future interactions with its allied partner as well as the healthiness of the existing cooperation (Choo, et al. 2009).

Trust and co-operation are critical factors that affect level of the success and outcomes of strategic alliances (Digman and Parast, 2007). Prajogo et al., (2012) found that there is a positive correlation between the strategic alliance trust (SAT) and strategic alliance operational performance which impacts on its costs and outcome performances.

Finally, the majority of previous studies have focused on profit-seeking firms as atomistic players. But, strategy researchers, who rely on economic perspectives underlying transaction cost economics (TCE) argue that the focus on TEC can contribute to SA competitive advantage.

\section{Strategic Alliance Motivations (SAM)}

A specific reason for the increased attention placed on interorganizational relationships is difficult to pinpoint.But, there are as many possible benefits to the formation of an interorganizational relationships alliance as there are motives for entering into these collaborative relationships. Heide and Stump (1995) address the issue of benefits and motives by stating that alliances are based on the «assumption that relationships are established in order to enhance some aspect of performance». Nevertheless, research on performance objectives of firms entering into alliances and the resulting achievements is severely lacking (Elmuti et al., 2005), as is the understanding of what types of alliances exist and what are the unique motives underlying the development these different types.

The SAM has received growing interest during the last several years. Previous studies has identified different strategic alliance motivations explained from a variety of theoretical perspectives, including transaction cost economics (Williamson, 1985; Hennart, 1991), resource dependency (Pfeffer\& Nowak, 1976), organizational learning (Grant, 1996), strategic positioning (Porter \& Fuller, 1986) and institutional theory (Meyer \& Rowan, 1977). Costs and risks sharing, entering new markets and achieving competitive advantages (Elmuti et al. 2005). Technological motives is also recent discussed motive (Taylor, 2005). As shown in Figure 1, (Zineldin and Dodourova, 2005) summarized and synthesize the motives for strategic alliances into four categories: financial, technological, managerial and strategic as follows:

1) FM: Financial motivation - we classify in this category motives related to cost reduction and profit generation (e.g. joint investment, reduced inventory).

2) TM: Technological motivation - motives that facilitate the supply process (e.g. sharing technology, joint new technological advances).

3) MM: Managerial motivation - such motives as interdependence, supply base reduction and loyalty, managerial effectiveness.

4) SM: Strategic motivation - motives that are related to competitive positioning of the supply process (e.g. future direction, achieving core competency). 


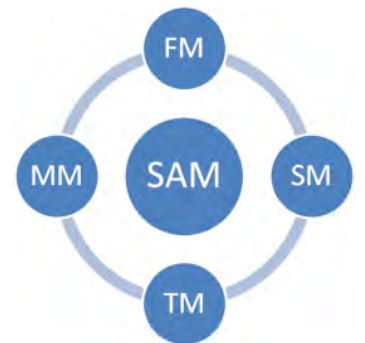

Figure 1 - Four Motives of Strategic Alliance (SA)

Although, learning and internalization of core competencies is one of the key motives behind alliance strategies (Taylor, 2005), strategic alliances often result in failure because of human resource management during the post-alliance integration period (Yalabika, 2013). However, enhancing knowledge about the positive and negative outcomes of the SA should direct future research and contribute to a reduction in alliance failures through improved managerial practices (Ireland et al., 2002). SA should sustain common goals, strategies, and pursued these collectively (Sebalj et al., 2007).

\section{Transaction Cost Economics (TCE) Theory}

Transactional economies can simply be defined as the process of savings in the process of exchange of intermediate inputs. In such an event, firms emerge as organisations that challenge the market as an alternative mechanism for governing transactions.

A different issue involves the design of strategic alliances based on a transaction cost economics (TCE) and transaction benefits perspectives (Williamson 1975). To account for the emergence of strategic alliances as well as their operation, a number of theories and models have been proposed, such as transaction cost economics (Hennart, 1988; Williamson, 1985) and game theory (Parkhe, 1993).

In transaction cost economics, according to Das and Teng (2000) the decision of a firm's ownership focuses on minimizing the sum of transaction and production costs (Coase, 1937; Williamson, 1975). Many researchers, howver, suggest that strategic alliances should be preferred when the transaction costs associated with an exchange are intermediate and not high enough to justify vertical integration (Gulati, 1995).

There are common factors between TCE and game theory where the parties of, for instance, a strategic alliance contract are assumed to have an understanding of the strategic situation within which they are located and position themselves accordingly. According to Willismson (2007), «TCE views governance as a means by which to relieve the oppressive logic of «bad games», of which the prisoners' dilemma is an exemplar.»... «Economizing on transaction cost is taken to be the cutting edge, where this is implemented through the discriminating alignment hypothesis, to wit: transactions, which differ in their attributes, are aligned with governance structures, which differ in their cost and competence, so as to effect a transaction cost economizing outcome».

TCE reject the standard non-cooperative model because it rely on a cooperative game theory where all participants must realize a net cooperative gain over the non-cooperative status-quo equilibrium. If the ratio of excludable benefits is small, cooperative gains from improved efficiency can arise as allies form tighter linkages and sacrifice autonomy. Cooperation can take the form of in-creased investment spending, equipment standardization, common logistics, shared goals and strategies, coordinated activities, common infrastructure, and different collaborative projects (Sanler and Hartley, 2001). 
Strategic Alliance Outcomes (SAO)

nd Strategic Alliance Overall Performance (SAOP)

Partnerships, alliances, collaboration, and buyer/manufacturer relationships in general have received much attention during the 1990s. Reports from industry of shorter cycle times, fewer quality defects, reduced costs, and streamlined processes resulting from closer working relationships with manufacturers have suggested a clearer understanding of the major factors affecting Strategic alliance relationships.

To establish effective strategic alliance relationships, organizations are using manufacturer selection criteria such as product quality, product availability, delivery reliability, and product performance and continuous improvement efforts (Vonderembse, 1999).. Ho (1999), argues the following: «unless organizations learn to identify and reform strategic business processes they will never be able to exploit changes in the market place. Profitability, market share and goodwill are not bestowed on organizations by some divine right. Instead the market awards these benefits to organizations that listen to and satisfy the voice of the customer»».

In order to realize the full potential of such relationships, the organization needs to develop an appropriate and systematic strategic processes including activities and action plans to achieve an effective and sustainable economics of strategic alliance.

One way to achieve sound economics of strategic alliance is to ensure that partner firms are satisfied. The level of satisfaction experienced is the outcome of the interorganizational relationship (Anderson and Narus, 1990; Frazier, Spekman, and O'Neal 1988). Previous researchers have suggested that there is a positive relationship between cooperation, cost leaderships, profitability and satisfaction(Zineldin\&Jonsson, 2000). The cooperative efforts of SA should result in greater trust, efficiency and the achievement of goals, which leads to higher level of satisfaction. Social network studies investigating outcomes of interorganizational relationships haveexamined a variety of partner of overall collaboration performance and outcomes such as innovative outcomes (Shan, Walker, \&Kogut, 1994), technical and technological outcomes such as patents (Stuart, 1998), and reputation (Stuart, Hoang, \& Hybels, 1999) and gain a competitive advantage in comparison to their competitors.

Satisfaction is an emotional response to the difference between what partners are expect and what they ultimately receive or acheive. Satisfaction influences the market share and profitability of a firm and is an essential indicator of the profits of the SA partners. Studies show that when partners are asked for their assessment of overall SA performance - and, in particular, when they are asked to report their satisfaction with the SA - they evaluate not only the SA outcomes, but also the SA process. When entering an SA, each partner brings certain initial expectations about the interactions and the outcomes (Kumar and Nti, 1998), and may influence the emergence of new goals for the SA. A specific measure such as strategic goals fulfilment can also capture outcome performance. According to Arino (2003) «net spillover effects and overall performance satisfaction are single-item measures whereas strategic goal fulfilment is a composite one, respondents may reflect their general feeling about the SA in the former measures, but not in the latter. This underscores how important it is to develop new measures that capture process performance and unbundle it from outcome performance».

Partners in a strategic alliance can create new value by reducing the transaction cost, the uncertainty and the level of the financial and practical risks associated with the purchase or joint investment. In such a relationship, there is a great opportunity to gain access to vast information about common needs, aspirations and plans, which provides a substantial competitive advantage by strengthening strategic cooperation (Zineldin, 2004). 


\section{Hypotheses}

Based on the literature review and the foregoing discussion, the following hypotheses are proposed:

H1: There is a positive relationship between SAM and TCE

$\mathrm{H} 2$ : There is a positive relationship between SAO and TCE

H3: There is a positive relationship between SAT and TEC

H4: There is a positive relationship between SAOP and TEC

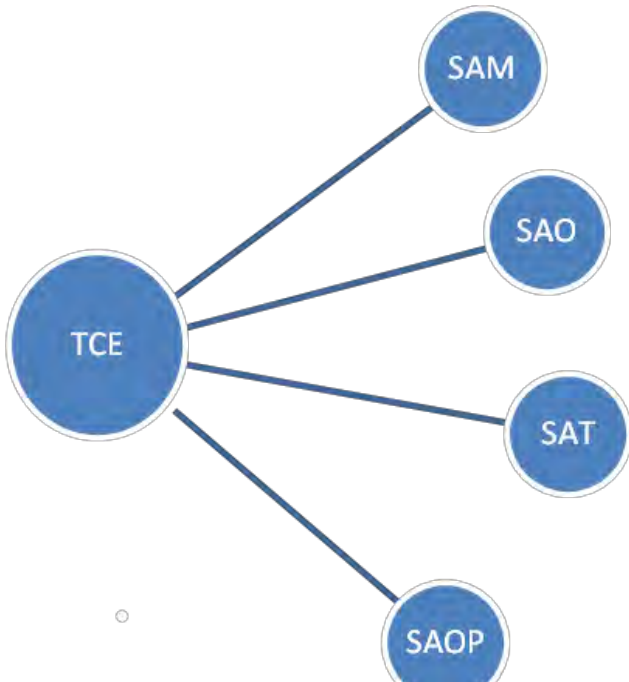

Figure 2: Research Hypotheses Transaction Cost Economics interrelation and correlation with SAM, SAO, SAT and SAOP

Recall that our hypothesized relationships are presumed to be relevant to any long-term interorganizations relationship which is difficult to terminate quickly.

\section{Methodology}

This research is based on a cross cultural approach which considers different industry sectors located in different countries - China, Japan and Mauritius. The choice of the countries is a result of our networks with different researchers in the above mentioned countries and the availability and access to the needed data. As part of the study, CEO's from Mauritian industries also participated in the survey. Although a small country in size, Mauritius is classified as a middle-income country with an emergent consumer market and ranks first in Africa for global competitiveness (World Economic Forum, 2013). It is often cited as an example for the African continent. The geographical spreading and cultural differences provide a good base for the generalisation of the study results and outcomes (Zineldinet al, 2015).

\section{The Sample}

The snowball sampling approach has successfully been used to gain respondents. According to snowball sampling, respondents are chosen from the professional and friendship networks of existing members of the sample (Thompson and Collin, 2002). The period of snowballing was 4 months. The questionnaire was designed as web-survey with a link to the survey platform or portal on line and as an e-mail survey. The respondents were encouraged to login with the specific password to conduct online reply or to return the answered survey to the researchers e-mail. By end of the three months a total of 112 (N 112) full completed questionnaires were received from respondents had strategic alliances with different suppliers, distributors and other supply chain actors. The sample profile is presented in Table 1. Most of 
the respondents were primarily male $(61,6 \%)$. Almost $44 \%$ had previous failure or experience of strategic alliance termination for different reasons.

Table 1 - Sample profile (N112)

\begin{tabular}{|c|c|c|c|}
\hline Variables/profile & $(\%)$ & Mean & Std d. \\
\hline Gender of the Senior executive & & 1,38 &, 489 \\
male & 61,6 & & \\
female & 38,4 & & \\
\hline Length of the alliance, SA & & 1,66 &, 823 \\
long (over 15 years) & 56,3 & & \\
medium (over 5 to 14) & 21,4 & & \\
short (less than 5) & 22,3 & & \\
\hline Size of the Organization & & 1,83 &, 899 \\
large & 49,1 & & \\
medium & 18,8 & & \\
small & 32,1 & & \\
\hline Native & & 1,74 & 1,02 \\
European & 57,2 & & \\
USA & 22,5 & & \\
Others & 9,6 & & \\
\hline Partner's nationality (Culture) & 10,7 & & \\
\hline
\end{tabular}

The majority of the existing strategic alliances (56,3\%) were very stable with long term partnership over 15 years. $49 \%$ were large companies with over 500 employees and $32 \%$ are small with 1-10 employees. 57,2 \% of the strategic alliance partners were national partners, 22,5 were European firms, 9,6 \% USA firms and 10,7\% Were form other countries.

\section{Scales}

Scales consisting of multiple items were developed to measure each of the TCE, SAM, SAO and SAOP construct. Given our conceptualization of strategic alliance trust (SAT) and commitment, it was essential that the measures captured both the importance of the SA relationship to respondents and their beliefs about working to maintain the collaborative SA. To the extent possible we draw upon scales which had been used in economics, management, social networks, psychology and marketing literature to further the process of validation for established scales. All constructs were measured through multiple-item scales and a 5-point Likert-type response format.

\section{Reliability and Validity}

One of the major concerns which must be addressed is whether the scales measure what they are supposed to measure. It is also necessary to test the degree of internal consistency, or degree of inter-correlation among several measures for the same construct (Zineldin et al, 2015). Some reliability and validity tests were conducted. Chronbach's coefficient alpha was used to assess the degree of internal consistency of within a particular scale. From a psychometric point of view, Alpha values of the study construct subscales have been validated in numerous studies, as well as in several different cultures (Zineldinet al, 2015). According to Churchill (1979) and Fornell and Larcker (1981), 0.70 or higher are considered to be acceptable, with 0.60 being acceptable for new scales. As shown in table 2, all scales exceeded this threshold. Some descriptive statistics are shown in table 2. 
Table 2 - Item Statics

\begin{tabular}{|r|r|c|c|r|}
\hline $\begin{array}{r}\text { N 112 } \\
\text { Construct }\end{array}$ & $\begin{array}{r}\text { No. of } \\
\text { items }\end{array}$ & Mean & SD & $\begin{array}{r}\text { Cronbac } \\
\mathrm{h} \alpha\end{array}$ \\
\hline TCE & 8 & 28,589 & 5,888 &, 652 \\
\hline SAM & 4 & 19,169 & 2,044 &, 737 \\
\hline SAO & 8 & 30,160 & 5,292 &, 632 \\
\hline SAT & 6 & 21,491 & 3,705 &, 679 \\
\hline SAOP & 6 & 22,812 & 2,3347 &, 688 \\
\hline \multicolumn{4}{|r}{}
\end{tabular}

Our five constructs of the 32 sub-item scales had a good reliability score (Cronbach $\alpha=0.76)$.

\section{ANALYSIS AND CONCLUSION}

Strategic alliance outcomes (SAO) was measured using both monetary outcomes, namely, profits, market share and nonmonetary outcomes, which included gains in reputation, learning, innovation, and patents. Strategic alliance trust (SAT) was using items such as keeping promises and sharing information. Strategic alliance motivations (SAM) was measured by financial motivation (FM), Technological motivation (TM), strategic motivation (SM) and Managerial motivation (MM). Strategic alliance overall performance (SAOP) was including satisfaction of the partners, cooperation and communication, fulfilling the planned and expected needs and goals, the positive outcomes are significantly outweigh the negative ones.

Table 3 shows the correlations between each of the dependent, i.e. TCE and independent variables. Majority of the bivariate correlations are positive and several of them are statistically significant. In particular, the correlations between the TCE and all other independent variables are all positive. Only SAM is not significant in relation to SAT and SAOP.

Table 3 - Correlation between scale variables Pearson Correlations

\begin{tabular}{|c|c|c|c|c|c|}
\hline & TCE & SAM & SAO & SAT & SAOP \\
\hline TCE & 1 & & & & \\
\hline SAM &, $247^{* *}$ & 1 & & & \\
\hline SAO &, $566^{* *}$ &, $458^{* *}$ & 1 & & \\
\hline SAT &, $361^{* *}$ &, 159 &, $423^{* *}$ & 1 & ${ }^{*}$ \\
\hline SAOP &, $549^{* *}$ &, 175 &, $286^{* *}$ &, $665^{* *}$ & 1 \\
\hline$* *$. Correlation is significant at the 0.01 level $(2-$ \\
tailed). \\
\hline
\end{tabular}

Table 3 also reveals several strong correlations between the transaction cost economics (TCE) and the strategic alliance outcomes $(\mathrm{SAO})(\mathrm{r}=.57, \mathrm{p}<0.00)$ as well as the strategic alliance overall performance (SAOP) $(\mathrm{r}=, 55, \mathrm{p}<0.00)$. The two strongest correlates of strategic alliance outcomes (SAO) were also TCE $(\mathrm{r}=, 57, \mathrm{p}<0.00))$ and strategic alliance motivation $(\mathrm{r}=, 46, \mathrm{p}<0.00)$. and object orientation construct $(\mathrm{r}=, 56, \mathrm{p}<0.00)$. The relations of the strategic alliance trust (SAT) construe were strongest with SAO $(r=, 42, p<0.00)$ and also TCE $(r=, 36, p<0.00)$ but not significant with SAM. The SAOP variable had SAT as the strongest correlation $(\mathrm{r}=, 67 \mathrm{p}<0.00)$ and weakest correlation with $\mathrm{SAO}(\mathrm{r}=, 29$, $\mathrm{p}<0.00)$ and no significance at all with SAM. SAM was, however, the weakest correlate of all other variables regarding the transaction cost Economic issues. 


\section{Regression}

The key dependent variable to test each of our hypotheses represented the strategic benefits that accrue to the focal organization from Strategic alliance collaboration. One composite measure for transaction cost economics (TCE) of the strategic alliance that included decreasing costs, decreasing prices, decreasing risks, lower fixed capital and sharing expenses and reducing competitive uncertainty, was created to test Hypotheses 1 through 4.

To test the research hypotheses, a regression was conducted for the dependent variables transaction cost economics (TCE) and all independent variables, SAM, SMO, SAT and SAOP. The collinearity between several of the independent variables, and the high bivariate correlations between the independent variables and the dependent variables, resulted in the fact that several strong regression models could be developed. The models presented in table 4 , only contain statistically significant variables, and explain high levels of variance in the dependent variable.Table 4 shows the regression results for the 4 hypotheses. SAM was not statistically significant, thus the H1 was not supported. SAT had a weak significant, thus H3 is weakly supported.

Table 4 - Regression model for the economics of SA

\begin{tabular}{|l|l|c|c|}
\hline Model & $\beta$ & $\mathrm{P}$ & $\mathrm{R}^{2}$ \\
\hline & & &, 509 \\
\hline SAO &, 527 &, 000 & \\
\hline SAOP &, 556 &, 000 & \\
\hline SAT &, 223 &, 023 & \\
\hline
\end{tabular}

Dependent Variable TCE

The identified independent variables entered in backward and forward procedures (with the same final model). The model shows that all variables are statistically significant. It explains $51 \%$ of the variance in TCE. In this test, the largest $\beta$ value was .56 which means that infrastructure (SAOP) makes strongest contribution to explaining the total success or achievement of the economics of strategic alliance. Strategic alliance outcomes (SAO) construct make also good contribution with $\beta, 53$. Strategic alliance trust (SAT) showed the lowest contribution with $\beta, 22$.

SAOP and SAO are the most important variable in the model. It is not very surprising that when the positive outcomes outweigh the negative ones is good indication for the sound economics of the strategic alliance. Satisfaction is also important SAOP's indicator to reflect the impact of the TCE approach. SAO represented by the monetary outcomes such as profits, market share and nonmonetary or soft outcomes such as reputation, learning and patents are major concern when partners inter a strategic alliance focusing on transaction cost economic theory.

\section{REFERENCES}

1. Arion, A, (2003), Measures of strategic alliance performance: an analysis of construct validity, Journal of International Business Studies, Vol. 34, PP. 66-79.

2. Coase, R. H. 1937. The nature of the firm.Economica, 4 (new series): 385-405.

3. Das. T. K., and Teng, B-S. (2000), A Resource-Based Theory of Strategic Alliances, Journal of Management, Vol. 26, No. 1, 31-61.

4. Gulati, R. 1995. Does familiarity breed trust? The implication of repeated ties for contractual choice in alliances. Academy of Management Journal, 38: 85-112.

5. Hennart, J.-F. 1988. A transaction cost theory of equity joint ventures. Strategic Management Journal, 9: 361-374. 
6. Heide, J.B, Stump, R.L. (1995), "Performance implications of buyer-supplier relationships in industrial markets: a transaction cost explanation", Journal of Business Research, $32,1,57-66$.

7. Elmuti, D., Abebe, M., \&Nicolosi, M. (2005). An overview of strategic alliances between universities and corporations. Journal of workplace Learning, 17(1/2), 115-129.

8. Ireland, R., D, Hitt, M. A., and Vaidyanath, D. (2002), Alliance Management as a Source of Competitive Advantage, Journal of Management, Vol. 28, No. 3, pp. 413-446.

9. Rai, R. K.(2013), A Co-opetition-Based Approach to Value Creationin Interfirm Alliances: Construction of a Measure and Examination of Its Psychometric Properties;Journal of Management, Vol.XXNo.X,pp. 1-37DOI: 10.1177/0149206313515525.

10. Sandler, T., Hartley, K. (2001). Economics of Alliances: The Lessons for Collective Action Journal of Economic Literature, Vol. 39, No. 3 (Sep), pp. 869-896.

11. Sebalj, D., Hudson, S., Ryan, J. \& Wight-Boycott, J. (2007), Alliance Through Change, Journal of Higher Education Policy and Management, Vol. 29, No.3,pp. 275-287.

12. Taylor, A. (2005) An operations perspective on strategic alliance success factors: An exploratory study of alliance managers in the software industry. International Journal of Operations \& Production Management, Vol. 25 No. 5, pp. 469-490.

13. Yalabika, Z. Y. (2013), Mergers and acquisitions: does organizational socialization matter?, Human Resource Development International, Vol. 16, No.5, pp. 519-537.

14. Williamson, Oliver. 1975. Markets and Hierar-chies: Analysis and Antitrust Implications: A Study in the Economics of Internal Organi-zation. NY: Free Press.

15. Parkhe, A. 1993. Strategic alliance structuring: A game theory and transaction cost examination of inter-firm cooperation. Academy of Management Journal, 36: 794-829.

16. Williamson, O. E. 1985. The economic institutions of capitalism. New York: Free Press.

17. Williamson, O. (2007), Transaction Cost Economics: An Introduction, Economic Discussion paper, Open Assessment open E. Journal, 2007:3.

18. Zineldin, M. and Jonsson, P. (2000), "An Examination of the Main Factors Affecting Trust/Commitment in Supplier-Dealer Relationships: An Empirical Study of Swedish Wood Industry", The TQM Magazine, Vol. 12, No. 4, pp. 245-265.

19. Zineldin, M. (2004),"Co-opetition: the organisation of the future", Marketing Intelligence \& Planning, Vol. 22. Iss 7. pp. $780-790$.

20. Zineldin, M., and Dodourova, M. (2005), "Motivation, achievements and failure of strategic Alliances: the case of Swedish auto-manufacturers in Russia", European Business Review, Vol. 17 No. 5, pp. 460-70.

21. Zineldin, M. Fujimoto , H., Li, Y., Kassan, H., Vasicheva, V., Yu, W. F. (2015), Why Do Both Marriages and Strategic Alliances Have Over $50 \%$ Failure Rate? A Study of Relationship Quality of Strategic Alliances in China, Japan and Mauritius ; International Journal of Strategic Business Alliance, Vol. 1, No. 1.

Статья поступила в редакциию 30 декабря 2015 года. 